\author{
Military Technical College \\ Kobry El-Kobbah, \\ Cairo, Egypt
}

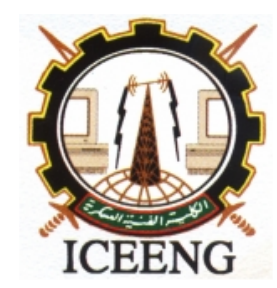

\author{
$7^{\text {th }}$ International Conference \\ on Electrical Engineering \\ ICEENG 2010
}

\title{
The Proposed Electric Circuit Diagram Of The Buried Bare Pipe Segment- Soil - Earth System With And Without Applying Cathodic Protection System
}

\author{
By \\ Dr. Ashraf Abdelraouf Mohamed Fouad Ahmed
}

\section{$\underline{\text { Abstract: }}$}

Based on proposed electrical concept of corrosion process, it is possible to simulate buried bare pipe segment with the surrounding soil medium by an electric circuit where the circuit electric quantities are function of the electrochemical properties of the soil as $4^{\text {th }}$ degree polynomial equations. The equivalent cylindrical electrolytic capacitor between the pipe and the remote earth and the potential across it, verifies the equation that charge $\mathrm{Q}=\mathrm{C} \times \mathrm{V}$ at natural condition with \& without applying cathodic protection system. The created positive charges consists with an equivalent negative charge (electrons losses) a charged stray electrolytic capacitor between the pipe and the earth through thin film soil layer around the pipe as cylindrical capacitor. The amounts of these charges are depending on the electrochemical properties of the soil which are surrounding the pipe segment, the length of the pipe segment and its diameter. The rate of discharge (equivalent to capacitor self discharge) is to be considered as the corrosion current. That's beside the facts deduced before that all electrical parameters prints \& equations are function of the electrochemical properties of soil medium around the pipe at different cathodic protection levels. The error of these new equations of the electrical parameters reduced to be less than $\pm 5 \%$. This will help to study both the corrosion problem and cathodic protection for a complete pipeline by an electric concept with an electric analogue circuit which is the aim of this study. This will help, in the future, in the choice of pipeline route, pipeline cathodic protection design and cathodic protection maintenance process for the pipe line along its route, however long it is.

\section{Keywords:}

Electrical study of pipe - soil - earth system 


\section{$\underline{\text { 1. Introduction }}$}

At humidity equal to zero, the soil medium around pipeline could be considered as a dielectric material which has its relative permittivity. If the humidity is increased, the soil medium is considered to be as an electrolyte associated with a change happened in the values of the relative permittivity, resistivity and $\mathrm{pH}$ of the soil. This change happened in the electrochemical properties of the soil will continue by increasing the humidity but these values will return back to their original values, or nearby initial values, after the humidity returns back to it's initial value. This nature of the soil medium between isolation medium and conduction medium according to the percentage of the humidity could be studied electrically.

In other words, if two dissimilar electrodes buried in a box which is containing a soil medium, a corrosion current will take place between these electrodes due to the difference in electrodes' natural potential while a capacitance in nano farad could be measured between these dissimilar electrodes (through the soil). The potential difference, the capacitance and the corrosion current between the positive and negative electrodes are electric quantities. Then, it may be possible to understand the corrosion and cathodic protection by an electrical concept beside the electrochemical and thermodynamic concepts. Now the corrosion may be described electrically by the equation: $(\mathrm{Q}=\mathrm{C} \times \mathrm{V})$, while the rate of discharge $\mathrm{dQ} / \mathrm{dt}$ is equal to the corrosion current from the +ve electrode to the -ve one [1] [2]. The same concept could be applied on the system of buried pipeline and the surrounding soil medium. The pipeline may be considered the +ve electrode while the remote earth may be considered the -ve electrode. In case of pipe-soil-earth system which is not subjected to any external interference, it is possible to find a correlation between the electrical parameters and the electrochemical properties of the soil at different humidity and at many cathodic protection levels with the results to be considered as an electrical parameters print or as a data sheet of this pipe-soil-earth system [6] [7] [8] [9] [10]. These electrical prints will be recalculated if the pipe and/or soil are changed. The importance of these electrical prints are not only to help to deduce the proposed electrical circuit of the combination pipe-soil-earth system but also to define both the electrical parameters and the cathodic protection level of any buried pipe segment if the protection current and the electrochemical properties are measured at the pipe segment directly from the field.

\section{Literature Review}

The only way in which atoms of the metal may detach themselves from the surface and enter the solution is in the form of positively charged ions. In electrochemical concept of corrosion process, for buried metal pipe in the ground, the following equations describe the corrosion process: 


\section{At the anode}

$$
\mathrm{Fe} \text { (solid) } \rightarrow \mathrm{Fe}^{++} \text {(ion) }+2 \mathrm{e}^{-} \text {(electrons) }
$$

\section{At the cathode}

Then,

$$
\begin{array}{lll}
2 \mathrm{H}^{+} \text {(hydrogen ions) }+2 \mathrm{e}^{-} & \rightarrow \mathrm{H}_{2} \text { (gas) } \\
\text { Or } \quad 2 \mathrm{H}^{+}+1 / 2 \mathrm{O}_{2}(\text { air })+2 \mathrm{e}^{-} & \rightarrow \mathrm{H}_{2} \mathrm{O} \\
\text { Or } \quad \mathrm{O}_{2}+2 \mathrm{H}_{2} \mathrm{O}+4 \mathrm{e}^{-} & \rightarrow 4 \mathrm{OH}^{-} \text {(hydroxyl ion) }
\end{array}
$$

$$
\begin{aligned}
\mathrm{Fe}^{++}+2(\mathrm{OH})^{-} & \rightarrow \mathrm{Fe}(\mathrm{OH})_{2} \\
\mathrm{Fe}^{+++}+3(\mathrm{OH})^{-} & \rightarrow \mathrm{Fe}(\mathrm{OH})_{3}
\end{aligned}
$$

In the proposed electrical concept of the corrosion process of bare pipe-soil system, the anodic reaction and the surrounding soil around the pipe may be represented, electrically, by formation of a charged electrolytic stray capacitor as shown in Fig.1 and Fig.2a [1] [2]. The electrolytic capacitor is consisting of pipe segment as the positive electrode, thin film of soil layer as the dielectric material of the capacitor and an imaginary co-axial earthing cylinder as the negative electrode. This is while for coating pipe-soil system, the stray capacitor may be considered as cylindrical capacitor with compound dielectric materials (coating of the pipe + thin film soil layer) as shown in Fig.2b [1] [2]. The formation of $\mathrm{Fe}(\mathrm{OH})_{2} \& \mathrm{Fe}(\mathrm{OH})_{3}$ in the electrochemical concept may be understood electrically by the positive charge discharged through the electrolytic stray capacitor to the imaginary co-axial earthing cylinder of radius $\mathrm{r}_{3}$ (self discharge of the capacitor). The rate of discharge is equal to the stray corrosion current (equivalent to electron loss).

In other words, the cathodic reaction at the imaginary co-axial earthing cylinder (the negative electrode) and formation of hydroxyl ion $\left(\mathrm{OH}^{-}\right)$, detach the positive ion from metal surface and form ferric oxides. Electrically, it may be understood as the discharge of the positive charge from the positive electrode to the imaginary grounded negative electrode through thin film of soil layer as shown in Fig.1. The above clarification could be summarized as follow:

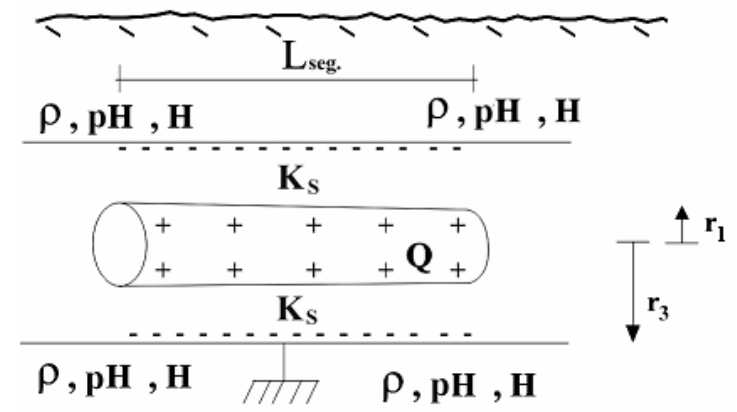

Figure 1: Proposed electrical concept of bare pipe segment with soil medium 


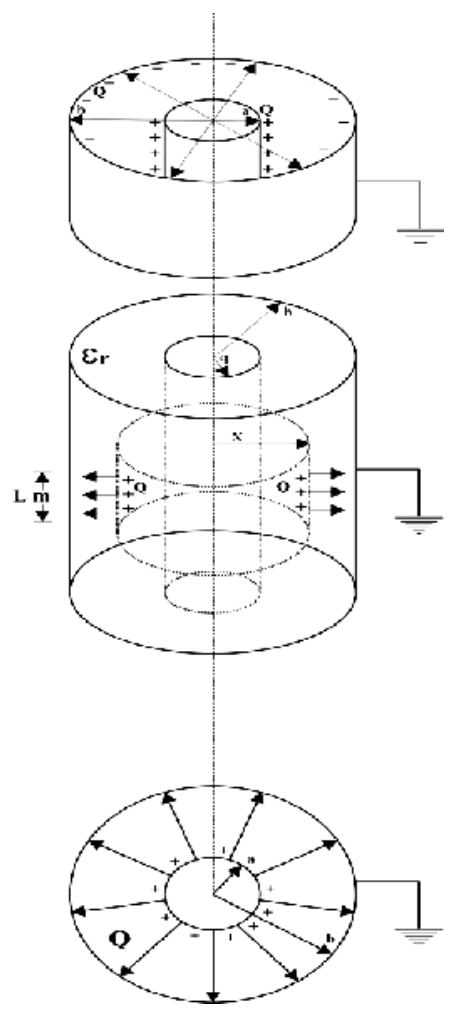

Figure 2a: Bare pipe segment with an imaginary Co-axial earthing cylinder form a charged electrolytic capacitor

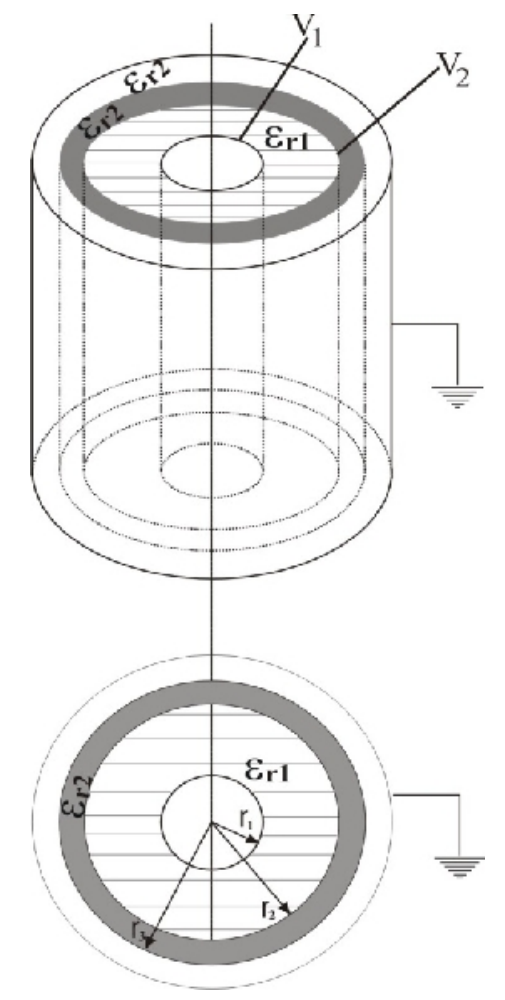

Figure 2b: Cylindrical capacitor of the pipe segment and the compound dielectric of coating material and soil layer

The electric concept of corrosion for pipe-soil-earth system may be written by the following proposed concept:

"Due to surrounding medium effect around metal structure buried in the ground, the charge created on metal outer surface area ( o.s.a ) builds up a potential through a stray electrolytic capacitor between metal o.s.a and an imaginary coaxial earthing cylinder where rate of discharge is equal to the corrosion current "[1][2].

The dielectric constant of the soil layer around the pipe $\mathrm{K}_{\mathrm{S}}$ acts with the dielectric constant of the pipe coating material $K_{C}$ as a coaxial cylindrical capacitor with compound dielectric. As $K_{C}$ of the coating material is decreased, the total capacitance value is decreased (two capacitors are in series) then charge is decreased .That's to say, the corrosion process (electrons losses) is decreased. If deterioration of coating material occurred, then $K_{C}$ is increased i.e. total capacitance value of the compound dielectric is increased .That's to say that corrosion process (electrons losses) is increased as the created charge on metal outer surface area $Q$ will be increased. This paper deduces the 
equivalent electrical circuit of bare pipe segment-soil-earth system with and without applying cathodic protection system.

\section{The Soil Factor}

As the values of the electrochemical properties of any soil medium are changed by the change of humidity, they return back to their initial conditions, or nearby the initial values, after some time, when humidity returns back to its initial value. Then we can define a new factor named the soil factor as:

"The soil factor is the instantaneous or present value of the electro-chemical properties of the soil based on the electrical properties at Humidity equal to 10\% "[1] [2]

The soil factor is equal to:

$$
\mathrm{S}_{\mathrm{f}}=(1 / \mathrm{Ks}) \mathrm{pHH} \log \rho \quad \text { at room temperature }
$$

Dimension of $\left[\mathrm{S}_{\mathrm{f}}\right]=\left[1 / \mathrm{K}_{\mathrm{S}}\right][\mathrm{pH}][\mathrm{H}][\log \rho]=. \mathrm{m} \%$

Where:

$$
\mathrm{S}_{\mathrm{f}}=\text { soil factor }
$$

$K s=$ Dielectric constant of the soil at $\mathrm{H}=10 \% \quad$ (a reference value of this property) $p H=$ power of Hydrogen of the soil

$\rho=$ Soil resistivity in $. \mathrm{m} . \quad$ at $\mathrm{H}=10 \% \quad$ (a reference value of this property)

$H=$ Humidity of the soil \%

Fig. 3 shows the range of the soil factor $S_{\mathrm{f}}$ and the range of humidity for ten soils under test.

The importance of this new parameter, the soil factor, is that it is combining all parameters which can affect directly on the cathodic protection level or in corrosion process (the effect of temperature and $\mathrm{CO}_{2}$ could be added in future studies). Such parameters which can be obtained by a direct measurement from the field only one time then use the humidity in the soil factor calculations. This means that if it is possible to study the relationship between the soil factor and the electrical parameters of the pipesoil system at natural condition with and without applying cathodic protection system, then the electrical parameters PRINTS of the pipe-soil-earth system could be obtained. The soil factor can be considered to be as the main key of many studies based on the proposed electrical concept of corrosion. For an example, the general equation of the natural stray capacitance, without applying $\mathrm{CP}$, between external surface area of bare 
pipe segment and earth is obtained in terms of the soil factor with an average error less than $\pm 5 \%$ and its print curves are obtained for pipe-soil-earth system for 10 different soils [3][10]. Also, the general equation of both the natural stray potential and the natural surface charge, without applying $\mathrm{CP}$, are obtained in terms of the soil factor with an average error less than $\pm 5 \%$ and their print curves are obtained for pipe-soilearth system for 10 different soils [4] [5] [10]. Also, by the use of this new parameter, the soil factor, it is possible to find a correlation between the electrical parameters and the electrochemical properties of the soil, with applying $\mathrm{CP}$, at different humidity and at many cathodic protection levels with the results to be considered as an electrical parameters print or as a data sheet of this pipe-soil-earth system [6] [7] [8] [9] [10].

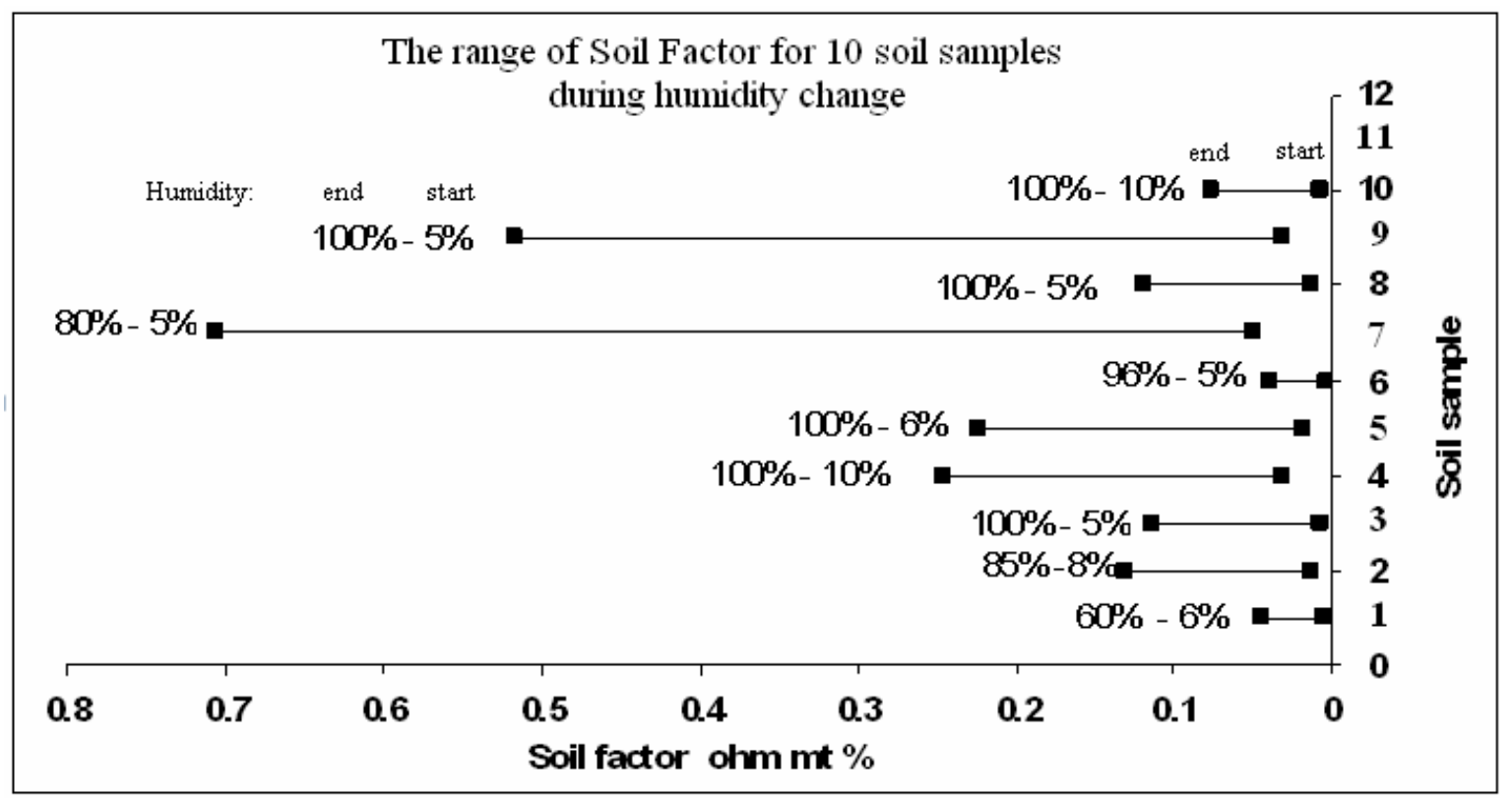

Figure 3: The range of the soil factor \& humidity range for the soils under test

\section{Case 1:}

4.1 Proposed Electrical Analogue Circuit Of The Pipe Segment - Soil - Earth System Without CP System [1] [2]

In a corrosion process, the metal pipe could be considered as a current source (stray corrosion current) to the surrounding medium (stray capacitor to the remote earth). The electrical analogue circuit of the pipe line segment with the surrounding medium effect could be represented as a current source connected in series with the stray capacitance between metal o.s.a and the remote earth. Consequently, the corrosion process could be electrically simulated for both bare pipe and at bad condition of coating material as shown in Fig.4. 
The general electrical analogue circuit of pipe segment-soil-earth system will consists of current source in series with an equivalent impedance $Z_{\text {eq. }}$ correlated to humidity ( $R_{\text {eq }}$ in parallel with $\mathrm{C}_{\mathrm{eq}}$ ) which is connected from pipe to the remote earth as shown in Fig.5. The importance of this proposed electrical circuit is that it converts both the corrosion and/or cathodic protection process into an electric problem. As we obtained before the electric parameters $\mathrm{C}, \mathrm{V}$ and $\mathrm{Q}$ of the bare pipe segment-soil-earth system in terms of the electrochemical properties of the soil i.e. the general equations of the natural stray capacitance [3],[10], the natural stray potential [4][10], the surface natural created charge[5][10]. All electrical parameters are deduced in terms of the soil factor, $4^{\text {th }}$ degree polynomial equations with an average error less than $\pm 5 \%$. In this paper, we will continue and use the results obtained before to deduce the electric analogue circuit of the natural condition pipe-soil-earth system without applying cathodic protection system.
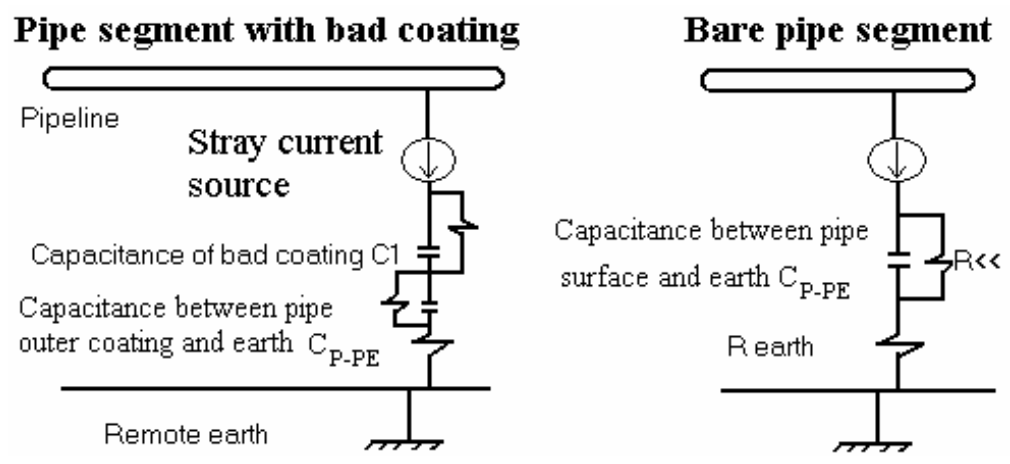

Figure 4: Proposed electrical analogue circuit of the pipe segment-soil system at the corrosion process

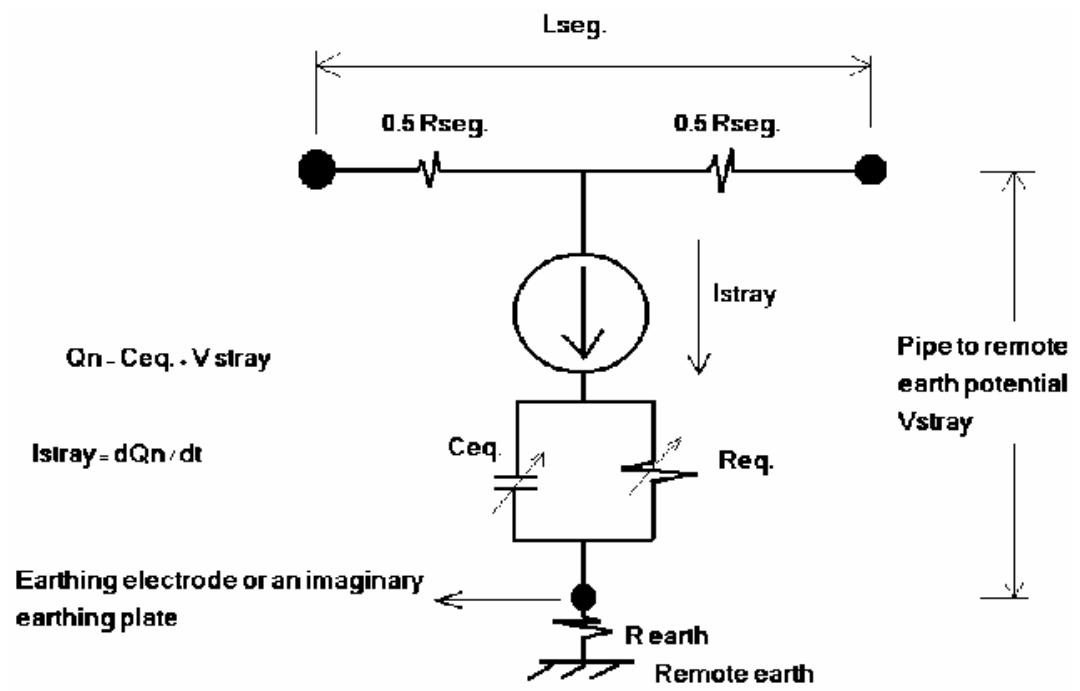

Figure 5: The proposed general electrical analogue circuit of pipe-soil system 
Proceedings of the $7^{\text {th }}$ ICEENG Conference, 25-27 May, 2010

\subsection{Calculations Of The Electrical Parameters Of The Pipe-Soil-Earth system Without Applying CP System}

Now, to obtain the pipe segment natural electric parameters without applying cathodic protection system, we have for the pipe-soil-earth system the following results:

\subsubsection{General Equation Of The Natural Stray Electrolytic Capacitor [3],[10]}

This is equal to Eq. 2:

Where:

$$
\mathbf{C}_{\mathbf{n} \text { stray }}=\mathrm{A}_{4 \mathrm{cn}} \mathbf{X}^{4}+\mathrm{A}_{3 \mathrm{cn}} \mathbf{X}^{\mathbf{3}}+\mathrm{A}_{2 \mathrm{cn}} \mathbf{X}^{\mathbf{2}}+\mathrm{A}_{1 \mathrm{cn}} \mathbf{X}+\mathrm{A}_{0 \mathrm{cn}}
$$

$\mathrm{A}^{\prime} \mathrm{s}=\mathrm{A}_{() \mathrm{CN}}$ are the stray capacitance PRINT constants of the pipe soil under test

$\mathbf{X}=$ instantaneous value of the electrochemical value of the soil, the soil factor

\subsubsection{General Equation Of The Natural Stray Potential [4],[10]}

This is equal to Eq. 3:

Where:

$$
\mathbf{V}_{\text {n stray }}=\mathrm{A}_{4 \mathrm{vn}} \mathbf{X}^{4}+\mathrm{A}_{3 \mathrm{vn}} \mathbf{X}^{\mathbf{3}}+\mathrm{A}_{2 \mathrm{vn}} \mathbf{X}^{2}+\mathrm{A}_{1 \mathrm{vn}} \mathbf{X}+\mathrm{A}_{0 \mathrm{vn}}
$$

A's: $=A_{() \text {v }}$ are the natural stray potential print constants of the pipe soil under test

$\mathbf{X}=$ instantaneous value of the electrochemical value of the soil, the soil factor

\subsubsection{General Equation Of The Natural Surface Charge [5],[10]}

This is equal to Eq. 4:

Where:

$$
\mathbf{Q}_{\mathbf{N}}=\mathrm{A}_{4 \mathrm{qn}} \mathbf{X}^{4}+\mathrm{A}_{3 \mathrm{qn}} \mathbf{X}^{\mathbf{3}}+\mathrm{A}_{2 \mathrm{qn}} \mathbf{X}^{\mathbf{2}}+\mathrm{A}_{1 \mathrm{qn}} \mathbf{X}+\mathrm{A}_{0 \mathrm{qn}}
$$

A's: = A ( ) qn are the surface natural charge print constants of the pipe - soil under test $\mathbf{X}=$ instantaneous value of the electrochemical value of the soil, the soil factor

\subsubsection{General Equation Of The Protection Current:}

As we consider the natural condition without applying cathodic protection system, then the rectifier output will equal to zero.

$$
\mathrm{I}_{\mathrm{P}}=0
$$




\subsubsection{The Earthing Resistance}

The earthing resistance $\mathrm{R}_{\mathrm{E}}$ could be easily measured from the field by the use of earth tester.

$$
\mathrm{R}_{\mathrm{E}}=\text { Measured from the field }
$$

\subsubsection{The Pipe Segment resistance}

The resistance of the pipe segment will equal to:

Where:

$$
\mathrm{R}_{\mathrm{SEG} .}=\left(1 / 4 \pi\left(\mathrm{D}_{\mathrm{O}}^{2}-\mathrm{D}_{\mathrm{I}}^{2}\right) * \mathrm{~L}_{\mathrm{SEG}} * \sigma_{\mathrm{IRON}}\right)
$$

$$
\begin{aligned}
D_{\mathrm{O}} & =\text { Outer diameter of the pipe segment } \\
\mathrm{D}_{\mathrm{I}} & =\text { Inner diameter of the pipe segment } \\
\mathrm{L}_{\mathrm{SEG}} & =\text { Length of the pipe segment } \\
\sigma_{\text {IRON }} & =\text { Iron specific resistance (pipe material) }
\end{aligned}
$$

\subsubsection{The Natural Stray Corrosion Current Calculation}

As per Eq. 4:

Then,

$$
\mathbf{Q}_{\mathbf{N}}=\mathrm{A}_{4 \mathrm{qn}} \mathbf{X}^{4}+\mathrm{A}_{3 \mathrm{qn}} \mathbf{X}^{\mathbf{3}}+\mathrm{A}_{2 \mathrm{qn}} \mathbf{X}^{\mathbf{2}}+\mathrm{A}_{1 \mathrm{qn}} \mathbf{X}+\mathrm{A}_{0 \mathrm{qn}}
$$

Rate of discharge $\mathbf{d} \mathbf{Q}_{\mathbf{N}} / \mathbf{d t}$ will equal to the corrosion current

$$
\mathbf{d} \mathbf{Q}_{\mathbf{n}} / \mathbf{d t}=\dot{\mathrm{x}}\left[\left(4 \mathrm{~A}_{4 \mathrm{qn}} \mathbf{X}^{\mathbf{3}}+3 \mathrm{~A}_{3 q \mathrm{qn}} \mathbf{X}^{\mathbf{2}}+2 \mathrm{~A}_{2 \mathrm{qn}} \mathbf{X}\right)+\mathrm{A}_{1 \mathrm{qn}}\right]
$$

As $\mathbf{X}=$ soil factor as per Eq.1, applying the $\mathbf{X}$ value in Eq. 8,

Then:

$$
\begin{aligned}
& \mathbf{d Q}_{\mathbf{n}} / \mathbf{d t}=\mathbf{I}_{\mathbf{S T R A Y}}=\dot{\mathrm{x}}\left[4 \mathrm{~A}_{4 \mathrm{qn}}\left(\left(1 / \mathrm{K}_{\mathrm{S}}\right) \log \rho\right)_{\mathrm{H}=10 \%}^{3}(\mathbf{p H . H})^{\mathbf{3}}+\right. \\
& 3 \mathrm{~A}_{3 \mathrm{qn}}\left(\left(1 / \mathrm{K}_{\mathrm{S}}\right) \log \rho\right)_{\mathrm{H}=10 \%}^{2}(\mathbf{p H . H})^{2}+ \\
&\left.2 \mathrm{~A}_{2 \mathrm{qn}}\left(\left(1 / \mathrm{K}_{\mathrm{S}}\right) \log \rho\right)_{\mathrm{H}=10 \%}(\mathbf{p H . H})+\mathrm{A}_{1 \mathrm{qn}}\right]
\end{aligned}
$$

Now, for bare pipe segment-soil-earth system under test, without applying any c.p system, without any external interference, at room temperature, with soil volume under test and by neglecting $\mathrm{CO}_{2}$ effect, the natural corrosion current from pipe surface to the surrounding medium could be obtained from an electrical concept of the corrosion and will equal to third order polynomial equation function of measured humidity and $\mathrm{pH}$ of the soil as shown in equation 9. 


\section{Natural corrosion current of the bare pipe segment to the surrounding medium $\mathbf{I}_{\text {STRAY }}$}

$$
I_{\text {STRAY }}=\dot{x}\left[B_{3 q n}(p H . H)^{3}+B_{2 q n}(\mathbf{p H} . H)^{2}+B_{1 q n}(p H . H)+A_{1 q n}\right]
$$

Where:

pH.H = Variable quantity equal to ( $\mathrm{pH} *$ Humidity) measured around the pipe segment

$\dot{\mathrm{x}}=$ Rate of soil factor change by time $\mathrm{dx} / \mathrm{dt}=\mathrm{d}\left(\mathrm{S}_{\mathrm{f}}\right) / \mathrm{dt}$

$\mathrm{B}_{3 q \mathrm{qn}}=$ Constant print equal to $4 \mathrm{~A}_{4 q \mathrm{qn}}\left(\left(1 / \mathrm{K}_{\mathrm{S}}\right) \log \rho\right)^{3}{ }_{\text {at } \mathrm{H}=10 \%}$

$B_{2 q n}=$ Constant print equal to $3 A_{3 q n}\left(\left(1 / K_{S}\right) \log \rho\right)^{2}$ at $\mathrm{H}=10 \%$

$\mathrm{B}_{1 \mathrm{qn}}=$ Constant print equal to $2 \mathrm{~A}_{2 \mathrm{qn}}\left(\left(1 / \mathrm{K}_{\mathrm{S}}\right) \log \rho\right)$ at $\mathrm{H}=10 \%$

$\mathrm{A}_{1 \mathrm{qn}}=$ Constant print from natural charge equation

$\mathrm{A}_{2 \mathrm{qn}}=$ Constant print from natural charge equation

$\mathrm{A}_{3 \mathrm{qn}}=$ Constant print from natural charge equation

$\mathrm{A}_{4 \mathrm{qn}}=$ Constant print from natural charge equation

$K_{S}=$ Constant equal to the dielectric constant of the soil at $\mathrm{H}=10 \%$

$\rho=$ Constant equal to the soil resistivity in . $\mathrm{m}$ at $\mathrm{H}=10 \%$

Referring to the proposed electrical circuit of bare pipe segment-soil-earth system in figures 5, the stray current source may be represented by equation 9 . Then, the final proposed electric circuit of such system may be as the circuit diagram shows in figure 6 taking into account that the pipe-soil-earth system is without applying cathodic protection system and without any external interference i.e. natural condition.

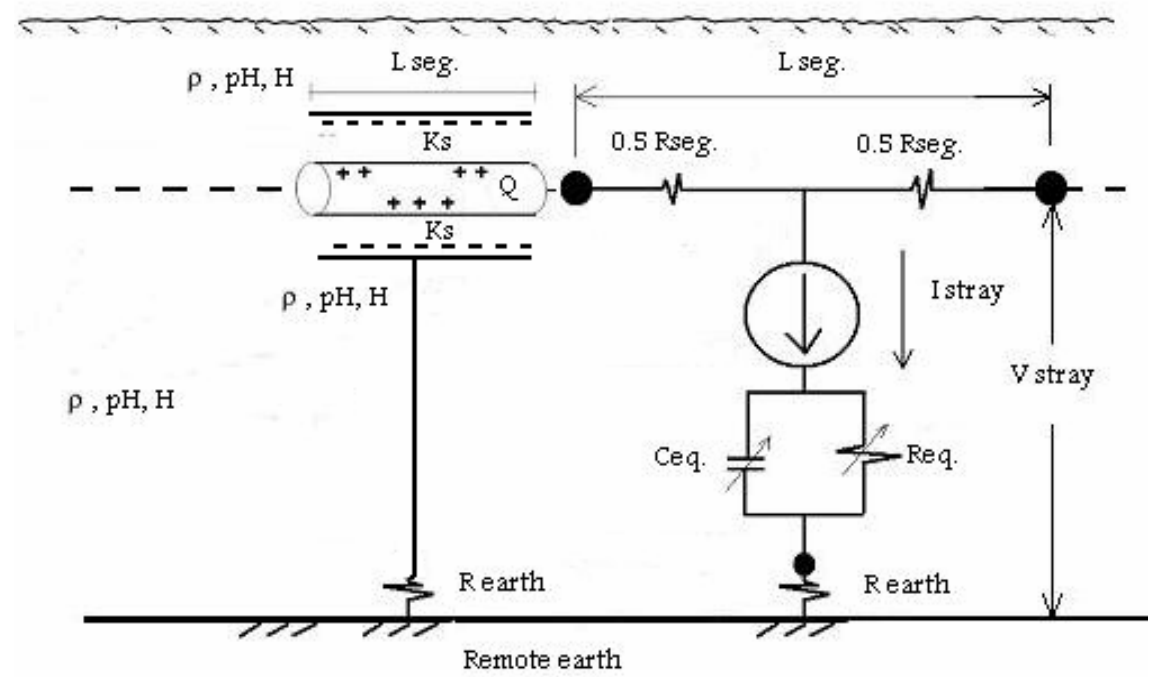

Figure 6: Final proposed electric circuit diagram of bare pipe segment-soil-earth system at natural condition without applying CP system 


\section{Case 2:}

\subsection{Proposed Electrical Analogue Circuit Of The Pipe Segment - Soil - Earth System With CP System [1][2]}

In case of cathodic protection process, the protection current either it is greater than the stray current (net current will flow through the pipe) or less than the stray current (net current will flow through the stray capacitor to the remote earth). The c.p level of the pipe line segment could be determined if the protection current before and after the pipe line segment is measured by using the proposed voltage drop canister pigged with an intelligent pig tool [1] [2]. For well coated pipe line segment, the electrical analogue circuit is as in Fig.7a. Also, Fig.7b shows the electric analogue circuit of the pipe segment which is cathodically protected by galvanic system or impressed current system Fig.7c.

The general electrical analogue circuit of pipe segment-soil-earth system will consist of current source in series with an equivalent impedance $Z_{\text {eq. }}$ correlated to humidity $\left(R_{\text {eq }}\right.$ in parallel with $\mathrm{C}_{\mathrm{eq}}$ ) which is connected from pipe to the remote earth as shown in figure 8 . The importance of this proposed electrical circuit is that it converts both the corrosion and/or cathodic protection process into an electric problem. As we obtained before the electric parameters $\mathrm{C}, \mathrm{V}$ and $\mathrm{Q}$ of the bare pipe segment-soil-earth system in terms of the electrochemical properties of the soil i.e. the general equations of the stray capacitance at many CP levels [6][10], the stray potential at many CP levels [7],[10], the surface total charge at many $\mathrm{CP}$ levels [8],[10] and finally the amount of the protection current at many CP levels [9],[10]. All electrical parameters deduced in terms of the soil factor, $4^{\text {th }}$ degree polynomial equations with an average error less than $\pm 5 \%$. In this paper, we will continue and use the results obtained before to deduce the electric analogue circuit of the natural condition pipe-soil-earth system with applying cathodic protection system.

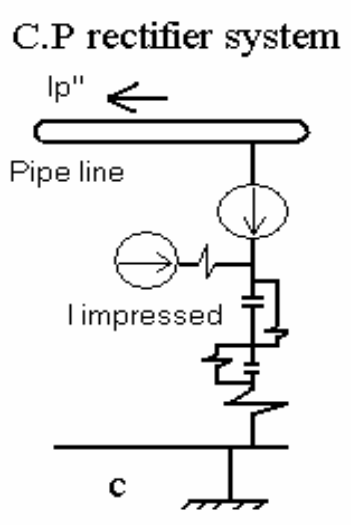

Remote earth
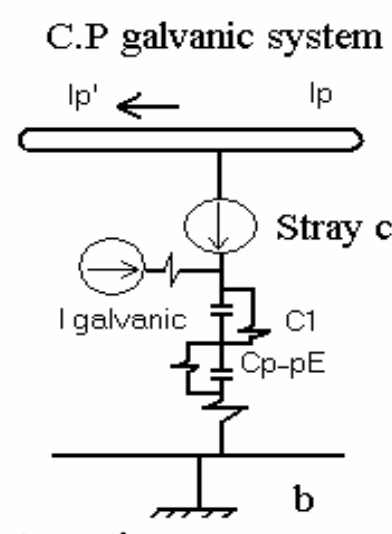

Remote earth

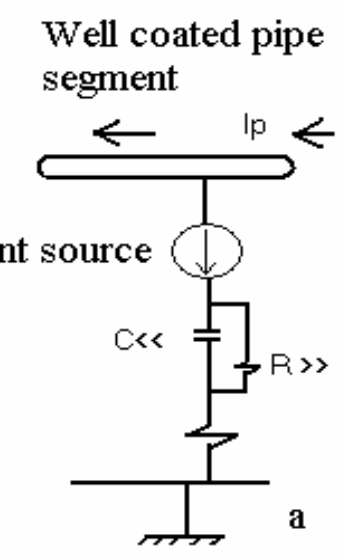

segment Figure 7: Proposed electrical analogue circuit of the pipe segment-soil system at the
$\begin{array}{llll}\text { cathodic protection process } & \text { (a) By well coating material } & \text { (b) By galvanic system }\end{array}$ (c) By using impressed current system 


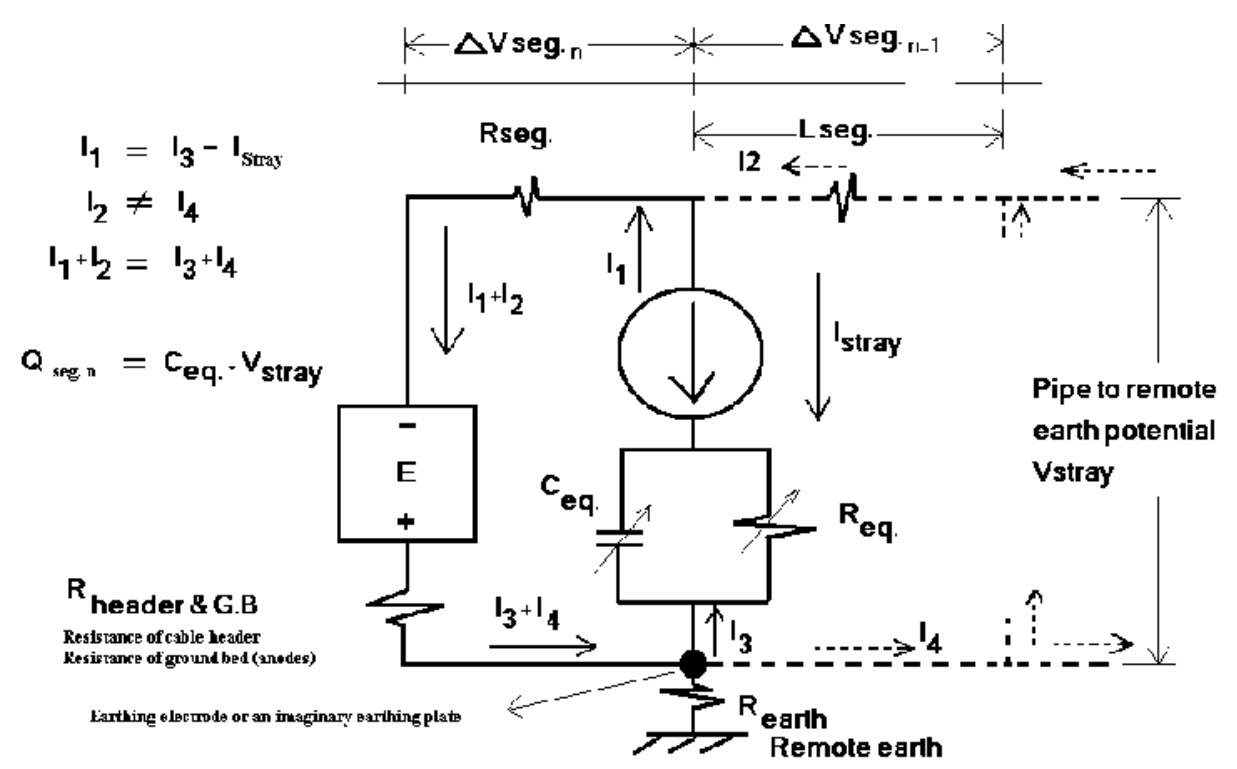

Figure 8: The proposed general electrical analogue circuit of pipe-soil system

\subsection{Calculations Of The Electrical Parameters Of The Pipe-Soil-Earth system With Applying CP System}

Now, to obtain the pipe segment natural electric parameters with applying cathodic protection system, we have for the pipe-soil-earth system the following results:

\subsubsection{General Equation Of The Electrolytic Capacitance [6][11]}

This is equal to Eq. 10:

Where:

$$
\mathbf{C}_{\text {stray }}=\mathrm{A}_{4 \mathrm{C}} \mathbf{X}^{4}+\mathrm{A}_{3 \mathrm{C}} \mathbf{X}^{3}+\mathrm{A}_{2 \mathrm{C}} \mathbf{X}^{2}+\mathrm{A}_{1 \mathrm{C}} \mathbf{X}+\mathrm{A}_{0 \mathrm{C}}
$$

$\mathrm{A}^{\prime} \mathrm{s}:=\mathrm{A}_{() \mathrm{C}}$ are the stray capacitance print constants of the pipe soil under test

$\mathbf{X}=$ instantaneous value of the electrochemical value of the soil, the soil factor

\subsubsection{General Equation Of The Stray Potential [7][11]}

This is equal to Eq. 11:

Where:

$$
\mathbf{V}_{\text {stray }}=A_{4 V} \mathbf{X}^{4}+A_{3 V} X^{3}+A_{2 V} X^{2}+A_{1 V} X+A_{0 V}
$$

$\mathrm{A}^{\prime} \mathrm{s}=\mathrm{A}_{() \mathrm{v}}$ are the natural stray potential print constants of the pipe soil under test

$\mathbf{X}=$ instantaneous value of the electrochemical value of the soil, the soil factor 


\subsubsection{General Equation Of The Surface Charge [9],[11]}

This is equal to Eq. 12:

Where:

$$
\mathbf{Q}=\mathrm{A}_{4 \mathrm{q}} \mathbf{X}^{\mathbf{4}}+\mathrm{A}_{3 \mathrm{q}} \mathbf{X}^{\mathbf{3}}+\mathrm{A}_{2 \mathrm{q}} \mathbf{X}^{\mathbf{2}}+\mathrm{A}_{1 \mathrm{q}} \mathbf{X}+\mathrm{A}_{0 \mathrm{q}}
$$

A's: = A ( ) q are the surface charge print constants of the pipe - soil under test

$\mathbf{X}=$ instantaneous value of the electrochemical value of the soil, the soil factor

\subsubsection{General Equation Of The Protection Current Flow To The Pipe Segment (I $\left.\underline{3}_{2}\right)$} [10][11]

This is equal to Eq. 13:

Where:

$$
\mathbf{I}_{3}=\mathbf{I}_{\mathbf{P}}=\mathrm{A}_{4 \mathrm{I}} \mathbf{X}^{4}+\mathrm{A}_{3 \mathrm{I}} \mathbf{X}^{3}+\mathrm{A}_{2 \mathrm{I}} \mathbf{X}^{2}+\mathrm{A}_{1 \mathrm{I}} \mathbf{X}+\mathrm{A}_{0 \mathrm{I}}
$$

$\mathrm{A}^{\prime} \mathrm{s}:=\mathrm{A}_{() \mathrm{I}}$ are the protection current print constants of the pipe soil under test

$\mathbf{X}=$ instantaneous value of the electrochemical value of the soil, the soil factor

\subsubsection{Natural Stray Corrosion Current I $\underline{S T R A Y}_{\text {[12] }}$}

This is equal to Eq. 14:

Where:

$$
\mathbf{d Q}_{\mathbf{n}} / \mathbf{d t}=\dot{\mathrm{x}}\left[\mathrm{B}_{3 \mathrm{qn}}(\mathbf{p H} . \mathbf{H})^{3}+\mathrm{B}_{2 \mathrm{qn}}(\mathbf{p H} . \mathbf{H})^{2}+\mathrm{B}_{1 \mathrm{qn}}(\mathbf{p H} . \mathrm{H})+\mathrm{A}_{1 \mathrm{qn}}\right]
$$

$\mathbf{p H . H}=$ Variable quantity equal to $\left(\mathrm{pH}^{*}\right.$ Humidity $)$ measured around the pipe segment

$\dot{\mathrm{x}}=$ Rate of soil factor change by time $\mathrm{dx} / \mathrm{dt}=\mathrm{d}\left(\mathrm{S}_{\mathrm{f}}\right) / \mathrm{dt}$

$\mathrm{B}_{3 \mathrm{qn}}=$ Constant print equal to $4 \mathrm{~A}_{4 \mathrm{qn}}((1 / \mathrm{Ks}) \log \rho)^{3}{ }_{\text {at } \mathrm{H}=10 \%}$

$\mathrm{B}_{2 q n}=$ Constant print equal to $3 \mathrm{~A}_{3 \mathrm{qn}}((1 / \mathrm{Ks}) \log \rho)^{2}{ }_{\text {at } \mathrm{H}=10 \%}$

$\mathrm{B}_{1 \mathrm{qn}}=$ Constant print equal to $2 \mathrm{~A}_{2 \mathrm{qn}}((1 / \mathrm{Ks}) \log \rho)$ at $\mathrm{H}=10 \%$

$\mathrm{A}_{1 \mathrm{qn}}=$ Constant print from natural charge equation

$\mathrm{A}_{2 \mathrm{qn}}=$ Constant print from natural charge equation

$\mathrm{A}_{3 \mathrm{qn}}=$ Constant print from natural charge equation

$\mathrm{A}_{4 \mathrm{qn}}=$ Constant print from natural charge equation

$K s=$ Constant equal to the dielectric constant of the soil at $\mathrm{H}=10 \%$

$\rho=$ Constant equal to the soil resistivity in. $\mathrm{m}$ at $\mathrm{H}=10 \%$ 


\subsubsection{Earthing Resistance}

The earthing resistance $\mathrm{R}_{\mathrm{E}}$ could be easily measured from the field by the use of earth tester.

$$
\mathrm{R}_{\mathrm{E}}=\text { Measured from the field }
$$

\subsubsection{Pipe Segment Resistance}

The resistance of the pipe segment will equal to:

Where:

$$
\mathrm{R}_{\mathrm{SEG} .}=\left(1 / 4 \pi\left(\mathrm{D}_{\mathrm{O}}^{2}-\mathrm{D}_{\mathrm{I}}^{2}\right) * \mathrm{~L}_{\mathrm{SEG} .} * \sigma_{\mathrm{IRON}}\right)
$$

$\mathrm{D}_{\mathrm{O}}=$ Outer diameter of the pipe segment

$\mathrm{D}_{\mathrm{I}}=$ Inner diameter of the pipe segment

$\mathrm{L}_{\mathrm{SEG}}=$ Length of the pipe segment

$\sigma_{\text {IRON }}=$ Iron specific resistance (pipe material)

\subsubsection{Calculation Of The Net Current Flow Through The Pipe Segment $\left(I_{1}+I_{2}\right)$ [9]}

\subsubsection{Calculation of Pipe Segment Flow Current}

As total surface charge is equal to;

$\mathbf{Q}_{\text {surface }}=\mathrm{A}_{4 \mathrm{q}} \mathbf{X}^{4}+\mathrm{A}_{3 \mathrm{q}} \mathbf{X}^{\mathbf{3}}+\mathrm{A}_{2 \mathrm{q}} \mathbf{X}^{2}+\mathrm{A}_{1 \mathrm{q}} \mathbf{X}+\mathrm{A}_{0 \mathrm{q}}$

Then, the pipe segment flow current, $\left(I_{1}+I_{2}\right)$ components as shown in Fig.8 is equal to: $\mathrm{dQ}$ surface $_{\mathrm{dt}}$

$\mathbf{d} \mathbf{Q}_{\text {surface }} / \mathbf{d t}=\dot{\mathrm{X}} \quad\left[4 \mathrm{~A}_{4 \mathrm{q}} \mathbf{X}^{\mathbf{3}}+3 \mathrm{~A}_{3 q} \mathbf{X}^{\mathbf{2}}+2 \mathrm{~A}_{2 \mathrm{q}} \mathbf{X}+\mathrm{A}_{1 \mathrm{q}}\right]$

From Eq. 1, applying the value of the soil factor as $X=S_{f}=\left(1 / K_{S}\right) p H H \log \rho$

Then:

$$
\begin{aligned}
& \mathbf{d Q}_{\text {surface }} / \mathbf{d t}=\dot{\mathrm{x}} \quad\left[4 \mathrm{~A}_{4 \mathrm{q}}((1 / \mathrm{Ks}) \log \rho)^{3}{ }_{\text {at } \mathrm{H}=10 \%}(\mathbf{p H . H})^{\mathbf{3}}+\right. \\
& 3 \mathrm{~A}_{3 \mathrm{q}}((1 / \mathrm{Ks}) \log \rho)_{\text {at } \mathrm{H}=10 \%}(\mathbf{p H . H})^{2}+ \\
& \left.2 \mathrm{~A}_{2 \mathrm{q}}((1 / \mathrm{Ks}) \log \rho)_{\mathrm{at}} \mathrm{H}=10 \%(\mathbf{p H} . \mathbf{H})+\mathrm{A}_{1 \mathrm{q}}\right]
\end{aligned}
$$

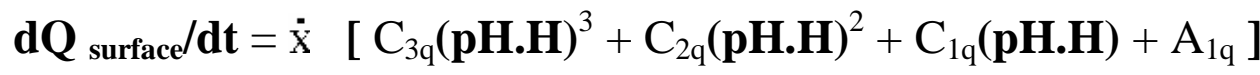


Now, for bare pipe segment-soil-earth system under test which applying c.p system, without any external interference, at room temperature, with soil volume under test and by neglecting $\mathrm{CO}_{2}$ effect, the flow current of the pipe segment-soil under test could be obtained from an electrical concept of the corrosion and will equal to third order polynomial equation function of the measured ( $\mathrm{pH}^{*}$ humidity) as shown in equation 18 .

\begin{tabular}{|c|}
\hline Flow current of the pipe segment under test \\
$\mathbf{I}_{1}+\mathbf{I}_{2}=\dot{\mathrm{x}}\left[\mathrm{C}_{3 \mathrm{q}}(\mathbf{p H} . \mathrm{H})^{3}+\mathrm{C}_{2 \mathrm{q}}(\mathbf{p H} . \mathrm{H})^{2}+\mathrm{C}_{1 \mathrm{q}}(\mathbf{p H} . \mathrm{H})+\mathrm{A}_{1 \mathrm{q}}\right]$
\end{tabular}

Where:

pH.H = Variable quantity equal to $\left(\mathrm{pH}^{*}\right.$ Humidity $)$ measured around the pipe segment

$\dot{\mathrm{x}}=$ Rate of soil factor change by time $\mathrm{dx} / \mathrm{dt}=\mathrm{d}\left(\mathrm{S}_{\mathrm{f}}\right) / \mathrm{dt}$

$\mathrm{C}_{3 \mathrm{q}}=$ Constant print equal to $4 \mathrm{~A}_{4 \mathrm{q}}((1 / \mathrm{Ks}) \log \rho)^{3}{ }_{\text {at } \mathrm{H}=10 \%}$

$\mathrm{C}_{2 \mathrm{q}}=$ Constant print equal to $3 \mathrm{~A}_{3 \mathrm{q}}((1 / \mathrm{Ks}) \log \rho)^{2}$ at $\mathrm{H=10 \%}$

$\mathrm{C}_{1 \mathrm{q}}=$ Constant print equal to $2 \mathrm{~A}_{2 \mathrm{q}}((1 / \mathrm{Ks}) \log \rho)$ at $\mathrm{H}=10 \%$

$A_{1 q}=$ Constant print from surface charge equation

$\mathrm{A}_{2 \mathrm{q}}=$ Constant print from surface charge equation

$A_{3 q}=$ Constant print from surface charge equation

$\mathrm{A}_{4 \mathrm{q}}=$ Constant print from surface charge equation

$K s=$ Constant equal to the dielectric constant of the soil at $\mathrm{H}=10 \%$

$\rho=$ Constant equal to the soil resistivity in. $\mathrm{m}$ at $\mathrm{H}=10 \%$

5.2.8.1Calculation Calculation of the Current Reaches the Pipe Segment from d-c

Source $\left(I_{3}\right)$

We have: $\quad \mathbf{Q}_{\text {surface }}=\mathbf{Q}_{\text {C.P }}-\mathbf{Q}_{\mathbf{n}}$

Then:

$d Q_{C P} / d t=d Q_{\text {surface }} / d t+d Q_{n} / d t$

As,

$\mathbf{d} \mathbf{Q}_{\mathbf{n}} / \mathbf{d t}=\dot{\mathrm{X}} \quad\left[\mathrm{B}_{3 q \mathrm{qn}}(\mathbf{p H} . \mathbf{H})^{3}+\mathrm{B}_{2 \mathrm{qn}}(\mathbf{p H} . \mathbf{H})^{2}+\mathrm{B}_{1 \mathrm{qn}}(\mathbf{p H} . \mathbf{H})+\mathrm{A}_{1 \mathrm{qn}} \quad\right]=\mathbf{I}_{\text {stray }}$

from Eq.(9) 
$\mathbf{d Q}_{\text {surface }} / \mathbf{d t}=\dot{\mathrm{x}}\left[\mathrm{C}_{3 \mathrm{q}}(\mathbf{p H} . \mathbf{H})^{3}+\mathrm{C}_{2 \mathrm{q}}(\mathbf{p H} . \mathbf{H})^{2}+\mathrm{C}_{1 \mathrm{q}}(\mathbf{p H} . \mathbf{H})+\mathrm{A}_{1 \mathrm{q}} \quad\right]=\mathbf{I}_{\mathbf{1}}+\mathbf{I}_{\mathbf{2}}$

from Eq.(17)

$\mathbf{I}_{1}=\mathbf{I}_{3}-\mathbf{I}_{\text {stray }}$

$\mathbf{I}_{\mathrm{DC}}=\mathbf{I}_{\mathbf{3}}+\mathbf{I}_{\mathbf{4}}$

In our case of pipe segment study, $\mathrm{I}_{4}=0 \& \mathrm{I}_{2}=0$

Then:

$$
\begin{aligned}
& \mathbf{d} \mathbf{Q}_{\mathrm{CP}} / \mathbf{d t}=\mathbf{I}_{\mathbf{D C}}=\dot{\mathrm{x}} \quad\left[\left(\mathrm{B}_{3 q \mathrm{n}}+\mathrm{C}_{3 q}\right)(\mathbf{p H} . \mathbf{H})^{3}+\left(\mathrm{B}_{2 \mathrm{qn}}+\mathrm{C}_{2 \mathrm{q}}\right)(\mathbf{p H} . \mathbf{H})^{2}+\right. \\
& \left.\left(\mathrm{B}_{1 \mathrm{qn}}+\mathrm{C}_{1 \mathrm{q}}\right)(\mathbf{p H . H})+\left(\mathrm{A}_{1 q n}+\mathrm{A}_{1 \mathrm{q}}\right)\right]
\end{aligned}
$$

$\mathbf{d Q} \mathbf{Q}_{\mathrm{CP}} / \mathbf{d t}=\mathbf{I}_{\mathbf{D C}}=\dot{\mathrm{x}}\left[\mathrm{D}_{3}(\mathbf{p H} . \mathbf{H})^{\mathbf{3}}+\mathrm{D}_{2}(\mathbf{p H} . \mathbf{H})^{2}+\mathrm{D}_{1}(\mathbf{p H} . \mathbf{H})+\mathrm{D}_{0}\right]$

Now, for bare pipe segment-soil-earth system under test which applying c.p system, without any external interference, at room temperature, with soil volume under test and by neglecting $\mathrm{CO}_{2}$ effect, the amount of rectifier current reaches the pipe - soil system under test could be obtained from an electrical concept of the corrosion and will equal to third order polynomial equation function of the measured ( $\mathrm{pH}^{*}$ humidity) as shown in Eq.19.

\section{Amount of rectifier current reaches the pipe segment under test}

$$
\mathbf{I}_{\mathbf{D C}}=\dot{\mathrm{x}}\left[\mathrm{D}_{3}(\mathbf{p H} . \mathbf{H})^{3}+\mathrm{D}_{2}(\mathbf{p H} . \mathbf{H})^{2}+\mathrm{D}_{1}(\mathbf{p H} . \mathbf{H})+\mathrm{D}_{0}\right]
$$

Where:

pH.H $=$ Variable quantity equal to $\left(\mathrm{pH}^{*}\right.$ Humidity $)$ measured around the pipe segment

$\dot{\mathrm{x}}=$ Rate of soil factor change by time $\mathrm{dx} / \mathrm{dt}=\mathrm{d}\left(\mathrm{S}_{\mathrm{f}}\right) / \mathrm{dt}$

$\mathrm{D}_{3}=$ Constant equal to $\left(\mathrm{B}_{3 \mathrm{qn}}+\mathrm{C}_{3 \mathrm{q}}\right)=4\left(\mathrm{~A}_{4 \mathrm{q}}+\mathrm{A}_{4 \mathrm{qn}}\right)((1 / \mathrm{Ks}) \log \rho)^{3}{ }_{\text {at } \mathrm{H}=10 \%}$

$\mathrm{D}_{2}=$ Constant equal to $\left(\mathrm{B}_{2 q \mathrm{n}}+\mathrm{C}_{2 q}\right)=3\left(\mathrm{~A}_{3 q}+\mathrm{A}_{2 q \mathrm{n}}\right)((1 / \mathrm{Ks}) \log \rho)^{2}{ }_{\text {at } \mathrm{H}=10 \%}$

$D_{1}=$ Constant equal to $\left(B_{1 q n}+C_{1 q}\right)=2\left(A_{2 q}+A_{2 q n}\right)((1 / K s) \log \rho)$ at $\mathrm{H}=10 \%$

$\mathrm{D}_{0}=$ Constant equal to $\left(\mathrm{A}_{1 \mathrm{qn}}+\mathrm{A}_{1 \mathrm{q}}\right)$

$K s=$ Constant equal to the dielectric constant of the soil at $\mathrm{H}=10 \%$

$\rho=$ Constant equal to the soil resistivity in .m at $\mathrm{H}=10 \%$

Referring to the proposed electrical circuit of the bare pipe segment-soil-earth system in figure 8 , all current values are now determined for the pipe segment-soil-earth system under test. 
Also the values of the equivalent stray electrolytic capacitor, the potential across it, the natural stray current source from the pipe segment, pipe segment net current flow and finally the amount of DC current share for the pipe segment are determined. Then, the final proposed electric circuit of such system may be as the electrical circuit diagram shown in figure 9 a \& $9 b$.

The electrical parameters of the bare pipe segment-soil-earth system under test with applying $\mathrm{CP}$ system are as follow:

\begin{tabular}{|c|c|c|}
\hline $\begin{array}{l}C_{\text {eq. }}=C_{\text {stray }} \\
V_{\text {stray }} \\
I_{\text {stray }} \\
I_{1} \\
I_{\text {DC }}=I_{3} \\
I_{2}=I_{4}=0\end{array}$ & $\begin{array}{l}= \\
= \\
= \\
= \\
= \\
=\end{array}$ & $\begin{array}{l}\mathrm{A}_{4 \mathrm{cn}} \mathbf{X}^{\mathbf{4}}+\mathrm{A}_{3 \mathrm{cn}} \mathbf{X}^{\mathbf{3}}+\mathrm{A}_{2 \mathrm{cn}} \mathbf{X}^{2}+\mathrm{A}_{1 \mathrm{cn}} \mathbf{X}+\mathrm{A}_{0 \mathrm{cn}} \\
\mathrm{A}_{4 \mathrm{v}} \mathbf{X}^{\mathbf{4}}+\mathrm{A}_{3 \mathrm{v}} \mathbf{X}^{\mathbf{3}}+\mathrm{A}_{2 \mathrm{v}} \mathbf{X}^{2}+\mathrm{A}_{1 \mathrm{v}} \mathbf{X}+\mathrm{A}_{0 \mathrm{v}} \\
\dot{\mathrm{X}}\left[\mathrm{B}_{3 \mathrm{qn}}(\mathbf{p H} \mathbf{H})^{3}+\mathrm{B}_{2 \mathrm{qn}}(\mathbf{p H} \cdot \mathbf{H})^{2}+\mathrm{B}_{1 \mathrm{qn}}(\mathbf{p H} . \mathbf{H})+\mathrm{A}_{1 \mathrm{qn}}\right] \\
\dot{\mathrm{X}}\left[\mathrm{C}_{3 \mathrm{q}}(\mathbf{p H} . \mathbf{H})^{3}+\mathrm{C}_{2 \mathrm{q}}(\mathbf{p H} \cdot \mathbf{H})^{2}+\mathrm{C}_{1 \mathrm{q}}(\mathbf{p H} . \mathbf{H})+\mathrm{A}_{1 \mathrm{q}}\right] \\
\dot{\mathrm{X}}\left[\mathrm{D}_{3}(\mathbf{p H} . \mathbf{H})^{3}+\mathrm{D}_{2}(\mathbf{p H} . \mathbf{H})^{2}+\mathrm{D}_{1}(\mathbf{p H} \mathbf{H})+\mathrm{D}_{0}\right] \\
\text { for pipe segment under test }\end{array}$ \\
\hline
\end{tabular}

Where:

A's, B's, C's and D's: are the PRINT constants of the bare pipe-soil-earth system

$\mathbf{X}$ : instantaneous value of the electrochemical value of the soil, the soil factor ( Eq.1)

$\dot{\mathrm{x}}=$ Rate of soil factor change by time $\mathrm{dx} / \mathrm{dt}=\mathrm{d}\left(\mathrm{S}_{\mathrm{f}}\right) / \mathrm{dt}$

$\mathbf{H}:$ is the measured humidity

$\mathbf{p H}$ : is the measured power of hydrogen

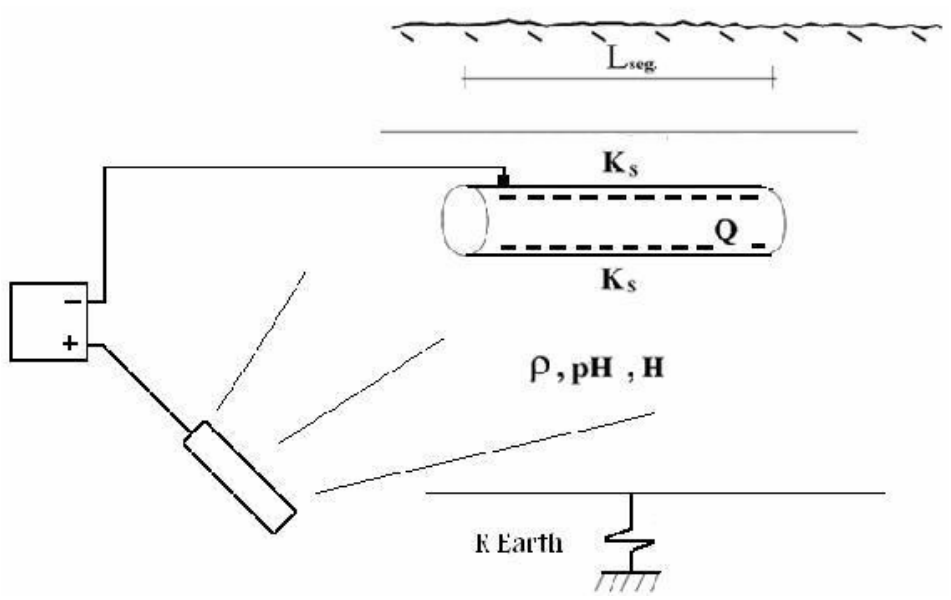

Figure 9a: shematic diagram of buried bare pipe segment with applying cathodic protection 


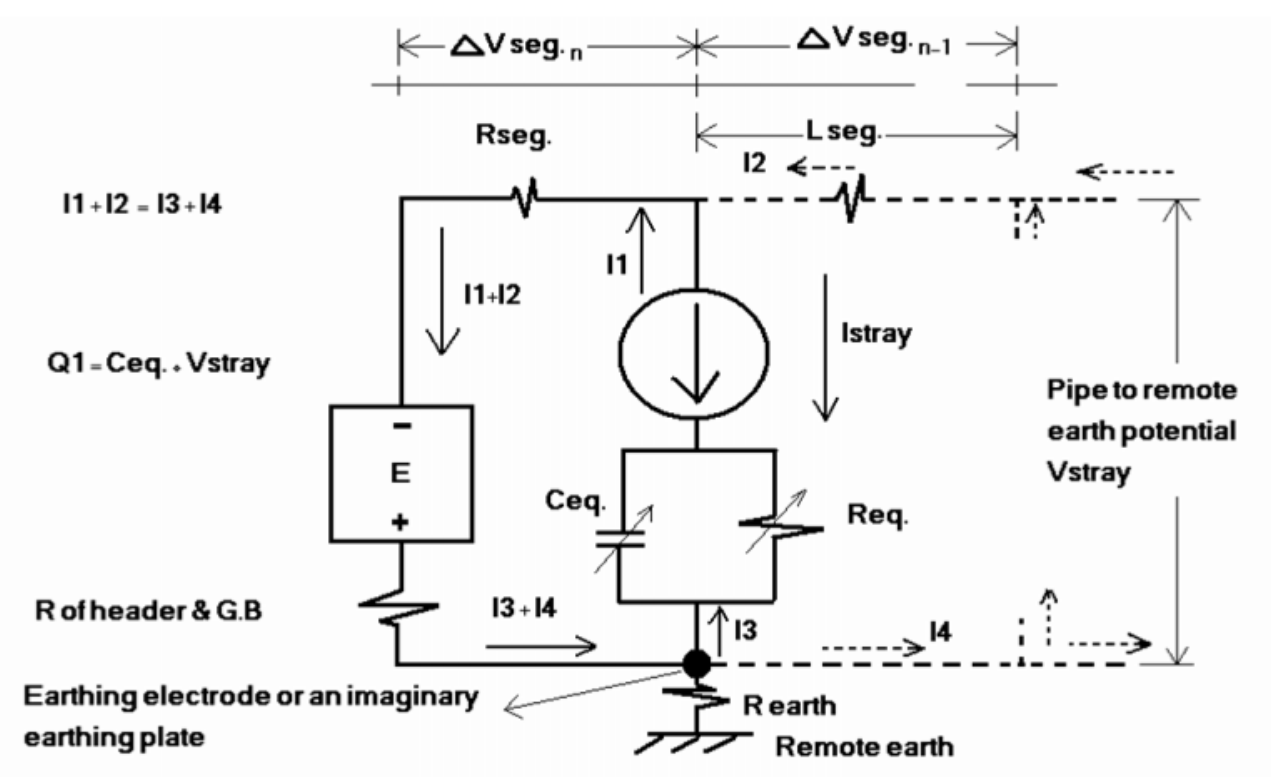

Figure 9b: The final proposed electric circuit diagram of bare pipe segment - soil earth system with cathodic protection system

\section{Circular $\Delta$ V PIG Idea: [1][2]}

This is a new idea of the voltage drop technique to measure the protection current $I_{P}$ passed through the buried pipeline. By considering a pipe line with total length $\mathrm{L} \mathrm{m}$, if such length is divided into segments with length $\mathrm{L}$ m./segment Then: Total length $\mathrm{L}=$ segment length $\mathrm{L}_{\mathrm{Seg}} \mathrm{x}$ number of segments $\mathrm{n}$ Electrically, the pipe line could be considered as: total resistance $=$ segment resistance $\times$ $\mathrm{n}$ as shown in Fig.10.

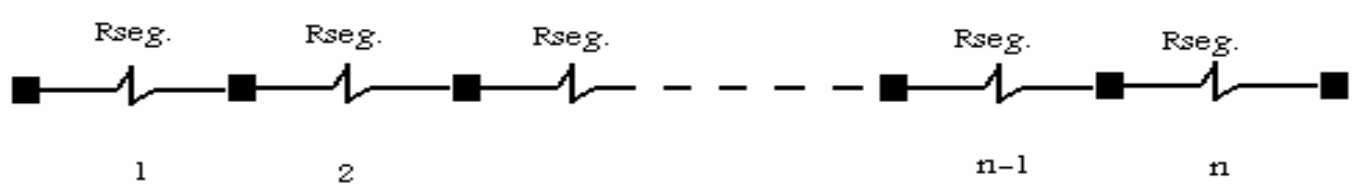

Figure 10: Electrical analogue resistance of the total pipe line length

Now if the voltage between points a $\&$ b of the segment is measured, as shown in figure 11, then the instantaneous measured protection current will equal to:

$\mathrm{Ip}=\frac{\mathrm{V}}{\mathrm{R}_{\text {seg }}}$

That means that an additional circular voltage drop canister could be added with the available intelligent pig to measure the protection current $\mathrm{I}_{\mathrm{P}}$. Figure 11 shows such 
canister, and in the meantime by using GPS technology to determine the segment position.

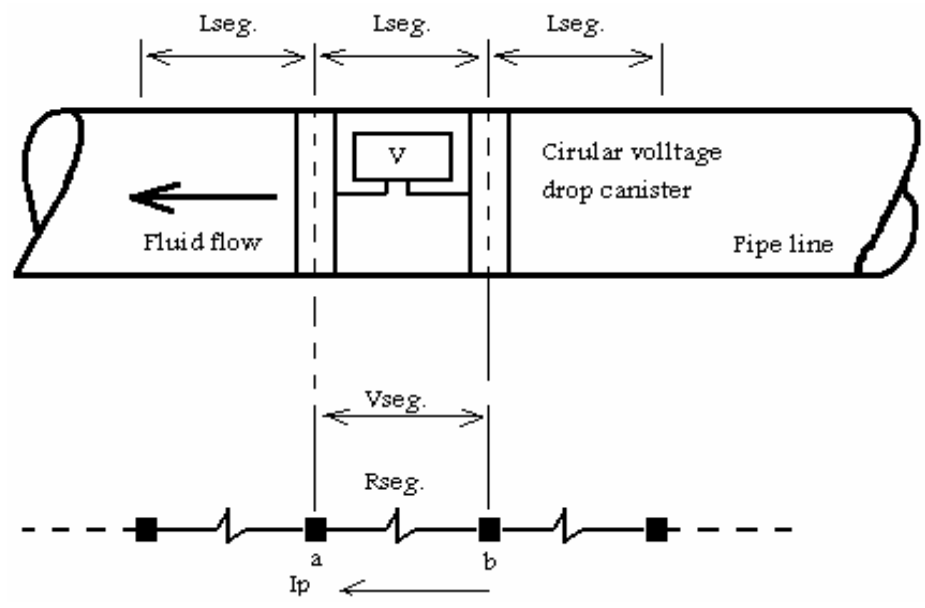

Figure 11: Idea of voltage drop canister to be pigged with the fluid through the pipeline

By the use of this voltage drop canister which pigged with the intelligent pig and by the use of GPS system, each segment flow current $I_{P}$ could be measured. Then by measuring the humidity around this pipe segment, the soil factor could be determined. Finally, from the ONION curves obtained before [9] (which correlate $\mathrm{I}_{\mathrm{P}}, \mathrm{S}_{\mathrm{F}}$ and $\mathrm{V}_{\mathrm{H} . \mathrm{C}}$ ), the equivalent pipe to soil potential of this buried pipe segment could be determined without the need of test point and without the need of $\mathrm{Cu} / \mathrm{CuSO}$ half cell. The most important result is that: the pipe to soil potential of any buried pipeline could be obtained segmental along its route without the need of any test points.

\section{Conclusion}

The behavior of the electrical parameters of the pipe-soil-earth system during the change of the electrochemical properties of the soil could be plotted in electrical parameters PRINT which will be always valid in all times as the pipe-soil system is maintained and without any external interference. Once the system is changed by replacement another pipe with different dimension and/or the replacement of the soil, there will be another new electrical parameters PRINT for the new pipe-soil-earth system. Also, the buried pipe line segment with soil surrounding medium could be simulated electrically by an electric circuit where the system is subjected to the law: (charge $=$ capacitance $\times$ volt) between the pipe surface and the remote earth. This is where each of circuit electric parameter could be obtained by an equation as a function of the measured electrochemical properties of the soil (soil factor), $4^{\text {th }}$ degree polynomial at room temperature but the A's constants are different for each electric quantity .The constants of each equation (A's) considered to be as a PRINT of such pipe-soil-earth system and 
valid until pipe and/or soil is changed with of course new print values. For buried bare pipe segments in different kind of soils at different cathodic protection level, the PRINTS of the electrolytic stray capacitor between pipe \& earth, the stray potential across the stray capacitance, surface charge and the protection current of the cathodic protection system passed through the pipe segment were obtained in terms of the new parameter, the soil factor. The useful of these prints is to obtain complete electrical data correlated with many cathodic protection levels which help, after complete erection of the pipeline, in defining the c.p level (pipe to soil potential) of any pipe line segment through it's length by measuring the protection current and calculating the soil factor at the pipe segment from direct field measurements. Not only has that but also to define the most suitable route of the pipe line, before the erection process, which generates the minimum surface charge. The error of electric parameters equations reduced to be less than $\pm 5 \%$. The most important advantage of such electrical analogue circuit of pipe segment-soil-earth system is the possibility to simulate a complete pipeline - soil system by an electric circuit and to convert both the corrosion and cathodic protection problems of the pipeline to an electric problem. This will help in corrosion monitoring and the maintenance of c.p systems. The most important result is that: the pipe to soil potential of any buried pipeline could be obtained segmental along its route without the need of any test points. This is by the use of the new electric concept of pipe-soil-earth system.

\section{Acknowledgement}

First and foremost, thanks to GOD the most kind, the most merciful and to whom any success is related.

\section{References:}

1. Ashraf Abdelraouf M. Fouad Ahmed, A Proposed Systematic Concept to Evaluate the Performance of Cathodic Protection of Buried Pipe Line in the Soil, The Egyptian Society of Chemical Engineers, TESCE, Cairo, Egypt, 2003

2. Ashraf Abdelraouf M. Fouad Ahmed, A Proposed Systematic Concept to Evaluate the Performance of Cathodic Protection of Buried Pipe Line in the Soil, International conference "Future Vision and Challenges for Urban Development", HBRC Cairo, Egypt, 2004 
3. Ashraf Abdelraouf M. Fouad Ahmed, The General Equation of the Natural Stray Capacitance between External Surface of Bare Pipe Segment and Earth, 25 Annual Conference Corrosion Problems In Industry, Egyptian Corrosion Society, ECS 2006.

4. Ashraf Abdelraouf M. Fouad Ahmed, The General Equation of the Natural Potential between External Surfaces of Bare Pipe Segment to Earth, $25^{\text {th }}$ Annual Conference Corrosion Problems In Industry, ECS 2006.

5. Ashraf Abdelraouf M. Fouad Ahmed, Deduction of The Natural Created Charge General Equation For A Buried Bare Pipe Line In The Soil, 25 ${ }^{\text {th }}$ Annual Conference Corrosion Problems In Industry, ECS 2006.

6. Ashraf Abdelraouf M. Fouad Ahmed, The General Equation and The Print Curves of The Stray Potential of a Cathodically Protected Buried Bare Pipe Segment, Ain- Shams University third international conference on environmental engineering, ASCEE-3, 2009.

7. Ashraf Abdelraouf M. Fouad Ahmed, The General Equation and The Print Curves of The Stray Capacitance of a Cathodically Protected Buried Bare Pipe Segment, Ain- Shams University third international conference on environmental engineering, ASCEE-3, 2009.

8. Ashraf Abdelraouf M. Fouad Ahmed, The General Equation and The Print Curves of The Total Surface Charge of a Cathodically Protected Buried Bare Pipe Segment, Ain- Shams University third international conference on environmental engineering, ASCEE-3, 2009.

9. Ashraf Abdelraouf M. Fouad Ahmed, The General Equation and The Print Curves of The Net Current Flow of a Cathodically Protected Buried Bare Pipe Segment, Ain- Shams University, ASCEE-3, 2009.

10. Ashraf Abdelraouf M. Fouad Ahmed, Experimental Natural Prints And The Recalculated General Equations Of The Electrical Parameters For Buried bare Pipe-Soil-Earth System With And Without Applying Cathodic Protection System, Under MTI Evaluation 